This item was submitted to Loughborough's Research Repository by the author.

Items in Figshare are protected by copyright, with all rights reserved, unless otherwise indicated.

\title{
What do driver educators and young drivers think about driving simulators?
}

\section{A qualitative draw-and-talk study}

\section{PLEASE CITE THE PUBLISHED VERSION}

https://doi.org/10.1016/j.trf.2019.01.008

\section{PUBLISHER}

(C) Elsevier BV

\section{VERSION}

AM (Accepted Manuscript)

\section{PUBLISHER STATEMENT}

This paper was accepted for publication in the journal Transportation Research Part F: Traffic Psychology and Behaviour and the definitive published version is available at https://doi.org/10.1016/j.trf.2019.01.008

\section{LICENCE}

CC BY-NC-ND 4.0

\section{REPOSITORY RECORD}

Rodwell, David, A.N. Hawkins, Narelle Haworth, Gregoire S. Larue, Lyndel Bates, and Ashleigh Filtness. 2019. "What Do Driver Educators and Young Drivers Think About Driving Simulators? A Qualitative Draw-and-talk Study". figshare. https://hdl.handle.net/2134/36857. 
1 A mixed-methods study of driver education informed by the Goals for Driver Education: Do young drivers and educators agree on what was taught?

3

4

\section{Abstract}

Evaluation research suggests that professional driver education and training has little effect on reducing the crash involvements of young drivers. Driver education and training programs have been criticised as being unsystematically designed and lacking an empirical or theoretical basis. The Goals for Driver Education (GDE) is a theoretical framework developed to address these criticisms. The GDE defines four hierarchical levels of driving behaviours and influences on driving and three individualised Person-specific factors that should be considered in driver education and training programs. The aim of this study was to compare and contrast, in a methodologically rigorous manner, the perceptions that young drivers ( $n=22 ; M_{\text {age }}=17.80$ years, $S D=6.54$ months $)$ and driver educators ( $n=10 ; M_{\text {age }}=54.5$ years, $S D=9.21$ years) have of a professional driver education and training course they participated in or facilitated. Eight semi-structured focus groups were conducted and the GDE was used to direct the collection and analysis of the data. Young drivers mainly discussed basic driving skills located on the lower levels of the GDE rather than higher level abstract factors that increase risk for young drivers. Driver educators tended to group particular GDE levels and Person-specific factors together when discussing the driving course and paid limited attention to Goals and contexts of driving. Results suggest that driver educators should provide direct instruction regarding the more abstract social and contextual factors that influence driving to potentially increase the efficacy of driver education and training as a safety countermeasure.

Keywords: Young drivers; Novice drivers; Driver education; Driver training; Goals for Driver Education; GADGET matrix; Graduated driver licensing 


\subsection{Introduction}

Road traffic injuries are the leading cause of death of individuals aged 15-29 years ( World Health Organisation, 2016). In 2015, in high income countries such as the United States and Australia, approximately $28 \%$ of deaths of $15-19$ year olds and $24 \%$ of $20-24$ year olds were caused by road injury (Institute for Health Metrics and Evaluation, 2015). Graduated Driver Licensing (GDL) programs, which regulate the type, time and contexts of driving for young people, have been adopted as the dominant governmental response to the issue of young driver crashes in North America and Australasia (Bates et al., 2014; Langley, Wagenaar, \& Begg, 1996; Senserrick \& Williams, 2015). Evaluations of GDL consistently demonstrate statistically significant, and often sizeable, reductions in young driver crash rates (Shope, 2007; Vanlaar et al., 2009). However, crash rates of young drivers remain high in comparison to experienced drivers even in jurisdictions with a GDL system (Bradshaw, Turner, Makwasha, \& Cairney, 2015). As such, further research and additional interventions are needed. This paper describes a mixed-methods study focused on professional driver education and training as a safety countermeasure for young drivers. The introduction is divided into three parts. First, an overview of young driver education and training research is provided. This is followed by a detailed explanation of a major theoretical framework about driver education and training, the Goals for Driver Education (GDE; Hatakka, Keskinen, Gregersen, Glad, \& Hernetkoski, 2002; Peraaho, Keskinen, \& Hatakka, 2003). Lastly, the aim of the study is presented.

\subsection{Driver Education and Training}

Driver education refers to the delivery of knowledge about driving and road safety and may not necessarily be conducted in a vehicle while driver training usually refers to the development of proficiency in specific skills (e.g. braking) (Beanland, Goode, Salmon, \& Lenné, 2013). A wide variety of approaches to both driver education and driver training have been developed (Raftery \& Wundersitz, 2011) and often elements of both driver education and driver training are presented within a single program (Groeger, 2011). In practice, it can be difficult to differentiate between 
driver education and driver training and research often conflates these terms (Raftery \& Wundersitz, 2011; Royal Automobile Club of Victoria, 2016).

Formalised driver education and training with professional instructors has a high level of face-validity (Lonero, 2008). It is likely that many organisations providing these courses, and the parents of attendees, have the expectation that these courses will increase young drivers' skills and, in doing so, reduce the chance that they will experience a motor vehicle crash (Mayhew, Simpson, \& Robinson, 2002). Despite this, most evaluation research indicates that participation in professional driver education and training has not lead to significant reductions in crashes of young drivers (Christie, 2001; Elvik, Hoye, Vaa, \& Sorenson, 2009; Glendon, McNally, Jarvis, Chalmers, \& Salisbury, 2014; Haworth, Kowadlo, \& Tingvall, 2000; Ker et al., 2005; Lonero \& Mayhew, 2010; Lund, Williams, \& Zador, 1986; Mayhew, et al., 2002; Mayhew, Simpson, Williams, \& Ferguson, 1998; Roberts \& Kwan, 2001; Thomas III, Blomberg, \& Fisher, 2012). Moreover, studies that have specifically examined skid training indicate that it does not reduce young driver crashes or violations and may actually increase risky driving behaviour and young driver crashes (Farmer \& Wells, 2015; Gregersen, 1996).

Researchers have sought to determine inter-individual differences that are most characteristic of young drivers involved in crashes (Engstrom, Gregersen, Hernetkoski, Keskinen, \& Nyberg, 2003; Shope \& Bingham, 2008). These characteristics may include core attributes and modifiable attributes of the person, other higher-order cognitive skill levels, as well as the type of driving in which young people engage (Bates, Davey, Watson, King, \& Armstrong, 2014). Core attributes may include differences in age and gender (Monárrez-Espino, Hasselberg, \& Laflamme, 2006), personality (Constantinou, Panayiotou, Konstantinou, Loutsiou-Ladd, \& Kapardis, 2011), and experience of clinical disorders, such as Attention Deficit Hyperactivity Disorder (Merkel et al., 2013). Modifiable attributes may include driving experience (McCartt, Mayhew, Braitman, Ferguson, \& Simpson, 2009) and the type and amount of driver education and training that an individual has received (Tronsmoen, 2008, 2010). Higher-order cognitive skills may include executive functions 
such as response inhibition (Mäntylä, Karlsson, \& Marklund, 2009) and hazard perception abilities (Borowsky, Shinar, \& Oron-Gilad, 2010). Research such as this implies that driver education and training efforts aimed at reducing young driver crashes should specifically incorporate elements that account for these important individualised influences on driving as well as procedural driving skills. One prominent reason that professional training has not led to expected safety benefits for young drivers may be that traditional training has targeted less relevant skills or those that are not the most important causal contributors to young driver crashes (Mayhew, et al., 2002). A second reason is that driver education and training programs have often been devised in an ad hoc manner without a scientific basis (Beanland, et al., 2013; Hoeschen et al., 2001; Peck, 2011). The GDE, also known as the GADGET matrix, was designed to broaden the scope of driver education and training and address these concerns (Hatakka, et al., 2002).

\subsection{The Goals for Driver Education}

The GDE is an organising framework for information about driver behaviour, training and skills development, and other areas of relevance for driver education and training practitioners (Berg, 2006). It aims to identify the driving skills and abilities that need to be acquired in order to become a safe driver and the factors that influence the learning process in attaining these skills and abilities (Hatakka, et al., 2002). The GDE groups driving behaviours and influences into four hierarchical levels which range from concrete and driving-specific to abstract and general (Peraaho, et al., 2003). The first level focuses on vehicle manoeuvring and is concerned with training requirements for the physical operation of the motor vehicle. Level two refers to mastering traffic situations and is concerned with an individual's ability to adapt to circumstances while driving. The third level is more abstract and centres on a person's motivations, goals and contexts of driving. The fourth level is very abstract and considers how driving fits within a person's life and is influenced by their personal development and other macro-contextual factors.

For the sake of categorisation within the GDE, the trip purpose (e.g. driving as a part of employment compared to driving to a place of employment), for example, would be included at 
level three while more global personality traits, media influence or macro-economic factors would be included at level four. However, items at each hierarchical level may have an influence on items at other levels either directly or indirectly (Peraaho, et al., 2003) and, while all aspects of the GDE are important, Hatakka, et al. (2002) suggest that targeting influences from the more abstract hierarchical levels may be of the greatest importance overall. Supporting this, young drivers obtain physical driving skills quickly (Hall \& West, 1996) and once automatized may be less likely to be the critical factor leading to young driver crash involvement compared to higher level influences such as decision-making errors (Curry, Hafetz, Kallan, Winston, \& Durbin, 2011) or intentional risk taking (Voogt, Day, \& Baksheev, 2014).

The GDE includes a mechanism that accounts for the training needs of individuals (Peraaho, et al., 2003). Three Person-specific factors are included in the framework which must be considered at each level of the hierarchy: Knowledge and skills; Risk-increasing factors; and Self-evaluation and awareness skills (Hatakka, et al., 2002). Knowledge and skills describes the informational content of each level and the methods with which that information is put into practice. Risk-increasing factors refer to individual attributes and other aspects that may increase an individual's risk of crashing. Finally, Self-evaluation and awareness skills refer to the level of insight an individual has about themselves, the environments and contexts in which they engage, and their skills. As a consequence of this structure, the hierarchical levels and Person-specific factors can be combined to form a matrix of twelve unique target areas. Table 1, adapted from Peraaho, et al. (2003), depicts the connection between each GDE level and Person-specific factor. An example item that falls into each of the twelve unique GDE level and Person-specific factor combinations is also provided.

Table 1.

The twelve aspects of focus for driver education and training within the Goals for Driver Education with examples

Knowledge and skills Risk-increasing factors Self-evaluation and




\begin{tabular}{|c|c|c|c|}
\hline $\begin{array}{l}\text { Goals for life and } \\
\text { skills for living } \\
\text { (Level Four) }\end{array}$ & $\begin{array}{l}\text { Knowledge of personal } \\
\text { tendencies that effect } \\
\text { driving }\end{array}$ & $\begin{array}{l}\text { Non-acceptance of } \\
\text { social norms regarding } \\
\text { drug use }\end{array}$ & $\begin{array}{l}\text { Ability to recognise and } \\
\text { control impulses }\end{array}$ \\
\hline $\begin{array}{l}\text { Goals and } \\
\text { contexts for } \\
\text { driving (Level } \\
\text { Three) }\end{array}$ & Ability to plan trips & $\begin{array}{l}\text { Risks associated with } \\
\text { driver condition }\end{array}$ & $\begin{array}{l}\text { Insight about time- } \\
\text { management skills }\end{array}$ \\
\hline $\begin{array}{l}\text { Mastery of traffic } \\
\text { situations (Level } \\
\text { Two) }\end{array}$ & Safety margins & $\begin{array}{l}\text { Driving skill in relation } \\
\text { to weather conditions }\end{array}$ & $\begin{array}{l}\text { Awareness of personal } \\
\text { driving style }\end{array}$ \\
\hline $\begin{array}{l}\text { Vehicle } \\
\text { manoeuvring } \\
\text { (Level One) }\end{array}$ & $\begin{array}{l}\text { Non-declarative } \\
\text { knowledge of how to } \\
\text { operate car }\end{array}$ & $\begin{array}{l}\text { Insufficient } \\
\text { automatization of } \\
\text { psychomotor skills for } \\
\text { operating the vehicle }\end{array}$ & $\begin{array}{l}\text { Realistic self-evaluation of } \\
\text { ability to reverse park }\end{array}$ \\
\hline
\end{tabular}

Adapted from Peraaho, et al. (2003)

122

\subsection{The Current Study}

The aim of the current study is to investigate the perceptions of driver education held by young drivers and the professional driver educators that work with them. What young drivers take away from professional driver education course may influence the subsequent way that they drive.

127 An understanding of the similarities and differences between the perceptions of professional driver education of these groups may lead to more effective, safety-focused, and theoretically supported driver education and training.

\section{Method}

\subsection{Context}

The study was conducted in the Australian state of Queensland in 2016. A GDL program operated in Queensland at the time of study (Queensland Department of Transport and Main Roads, 
2016; TMR) which consisted of a fully supervised learners licence, an independent but restricted provisional licence with two age and experience based levels (P1 and P2), and an unrestricted open licence. Young drivers could progress through the various licence categories over at least a four year period with the earliest starting age being 16 years.

This research was funded as part of an Australian Research Council Linkage Project (LP140100409). Linkage Projects aim to foster applied research and practical solutions to issues by promoting research involving both university and industry partners. The bulk of the funding is independent of each project partner ensuring that conflicts of interest are avoided. As such, the study was conducted with the assistance of a driver education and training organisation located in a regional Queensland city which provided a two day course for senior high school students (aged 1518 years). The course comprised a mixture of classroom and in-car activities including driving vehicles on a test track. While not a standardised or formalised requirement, individual driver educators would also often set 'homework' tasks to be completed after finishing the course. In this way, learnings were reinforced and opportunities for engagement of parents and other lay supervisors in the young drivers' experience of the course were provided. The nature of the course made it more accurately categorised as driver education rather than driver training, although as noted these terms are often used interchangeably. Additionally, the course included many elements of driver training and a strong focus on specific steering and braking techniques. For these reasons, the current study may provide insights for both driver education and driver training.

\subsection{Participants}

Twenty two young drivers ( $M_{\text {age }}=17.80$ years, $S D=6.54$ months; $50 \%$ female) participated in five focus groups. Young drivers ranged in age between 17 years and 2 months and 19 years and 1 month. The modal age of young drivers was 17 years and 9 months while the median age was 17.6 years. To participate, individuals were required to be 17 years or older, have completed the course in the preceding 3 years, and hold a current learners or provisional drivers licence. Most participants held a provisional licence $(\mathrm{P} 1=59.1 \% ; \mathrm{P} 2=22.7 \%)$ and most $(68.2 \%)$ had completed the course 
within the previous two years. Just over half (54.5\%) had completed the course while in Year 12, the final year of secondary education in Queensland. All young driver participants reported driving weekly and were currently driving an average of $6.23(S D=4.26)$ hours per week.

Young drivers in Queensland are likely to receive a mix of lay and professional driver training (Bates, Watson, \& King, 2014). However, professional driver education and training is not a legislated requirement in Queensland (TMR, 2016). It is possible that some young people in Queensland may gain an unrestricted licence solely through instruction by their parents or other lay supervisors. As such, young driver participants in this study were required to have completed the high school-based driver education course to ensure that both the driver educators and young drivers had a level of familiarity with professional driver education and training. Due to the nature of this population, it is likely that a large proportion of the young driver participants in the current study were either not yet licensed or were learners at the time they attended the course.

Ten driver educators ( $M_{\text {age }}=54.5$ years, $S D=9.21$ years; $90 \%$ male) participated in three focus groups. The driver educators' ages ranged from 37 to 64 years. The driver educators selfreported an average of 8.75 years ( $S D=7.70$ years $)$ in the driver education industry. All driver educators had current formal qualifications in driver education and training (e.g. TLI41210 Certificate IV in Transport and Logistics [Road Transport - Car Driving Instruction]). On average these participants worked 23.30 hours per week ( $S D=7.57$ hours) at the driver education provider, although this was unlikely to be solely presenting the high school driver course. Two participants also currently engaged in other driver training employment activities outside of the driver training organisation. The driver educators had held a driving licence (including learners) for 37.8 years (SD = 9.13 years) on average with a range of 21 to 48 years.

Young driver participants were recruited by email using a database maintained by the driver education and training provider or through word-of-mouth advertising to other individuals (e.g. teachers) who may have access to individuals fulfilling the inclusion criteria. Recruitment continued until data saturation was deemed to have occurred. Only driver educators employed the 
organisation who taught the specific high school course were recruited. All eligible driver educator participants chose to take part in the study. Other than providing assistance with recruitment of participants, the driver education organisation was not involved in any other aspect of the study, including its design and methodology, conducting the focus groups, or preparation of the manuscript. The organisation and its employees were not provided with any materials to be used in the focus groups prior to them occurring and were not advised of the aims and objectives of the study. Additionally, it should be noted that the driver education participants were all employed at the same organisational level and employees at management levels were specifically excluded from the study to reduce the potential for bias based on power differentials. Young driver participants were provided with an AUD\$15 gift card for attending. Driver educator groups were conducted at the organisation during existing work hours and participants were paid as normal for the time spent in the focus groups.

\subsection{Design and procedure}

Eight focus groups consisting of either young drivers (5 groups of 3-6 participants) or driver educators (3 groups of 3-4 participants) were conducted between January and July 2016. The young driver groups were conducted at convenient times for participants throughout this period, while the driver educators groups were conducted sequentially on a single day in January 2016. Groups were audio recorded and transcribed verbatim. Most groups were conducted during work hours on week days at the driver training organisation or at university facilities located in Brisbane. One young driver group was held in a quiet room at a church hall that was a convenient location for the participants.

The procedure for all groups was standardised. The focus group time was divided into two sections with the second section focusing on a different aspect of driver education. As such, the duration of discussions relevant for the current study ranged from 34 minutes to 1 hour and 22 minutes. Participants were greeted, the study purposes and ethical requirements explained, written consent was obtained, and a short demographics questionnaire (e.g. age, current licence etc.) was 
completed. Initial icebreaker questions were asked at the beginning of the focus groups. These questions probed about the course in general terms and allowed participants to become comfortable with the facilitators and the voice recorder. Examination of the GDE framework followed (see Table 2) and continued until it became evident that participants had nothing new to contribute. At the conclusion of the focus group, participants were asked if they had anything else to contribute. Immediately after each group, the facilitators held an informal debriefing session with each other where initial observations were discussed.

The design of the driver educator focus groups differed from the young driver groups in two ways. First, a short 10 minute presentation about the GDE framework was provided by the main facilitator immediately after discussion of the icebreaker questions. The driver educators were also given a handout detailing the GDE matrix, just prior to the presentation, which they could refer back to during the focus group. The GDE presentation was provided to the educators, and not to the young drivers, because it was recognised that the driver educators would have a higher level of knowledge about driver education and training but would most likely have little knowledge about the GDE. Also, in contrast to the young driver groups, it was decided that questions directly referencing the GDE would be the best approach for these individuals. This was because the driver educators have some expertise and engagement in the driver education and training field and thus are able to talk at a more abstract level about ideas related to the GDE. Care was taken to ensure that only a base level of information about the GDE was provided in the presentation and that language emphasising the importance of particular GDE components over others was avoided. Hatakka, et al. (2002)'s assertion that education and training about the higher levels or more abstract combinations of GDE components are possibly more important over the long term was not mentioned. The handout consisted of a single page with a figure explaining the GDE reproduced from Hatakka, et al. (2002) and a table from Peraaho, et al. (2003), similar to Table 1. As can be seen from in Table 2, the young drivers were asked indirectly about the GDE components using language 
appropriate to their age and level of understanding. Appropriate ethical clearance from university authorities was obtained prior to beginning the study (QUT: 1500001083; GU: 2016/879).

\subsection{Analysis and coding}

Little guidance has been provided regarding how the GDE can be used to accomplish its stated objectives of directing the design and evaluation of effective driver education and training programs. A method of operationalising the GDE was developed to examine participant perceptions of the content of an existing driver education and training program. As noted, the focus groups examined a range of aspects related to young driver education and training. The portions of the transcriptsthat were coded and analysed consisted of discussion that was: (1) was focused by the GDE question prompts; (2) occurred during the icebreaker section; and (3) occurred during the concluding sections of each group. Portions of the transcripts where discussion was focussed on other aspects of driver education were not coded. The analysis of audio transcripts was conducted using Nvivo 11 Pro (2016).

\section{Table 2.}

Question probes from the young driver and driver educator focus groups listed in the order they were presented to participants

\section{Young driver question probes}

What did the driver education course teach you about yourself when controlling a vehicle? Thinking about your current driving, how has what you learned at the driver education course influenced the way you think about yourself in different types of driving situations?

Would you say that attending the driver education course made you personally consider how more broad types of things, like having other passengers in the car, the mood you are in, or where you are headed to may underlie the way you choose to drive? How has the driver education course made you think about where driving will fit/fits into your life?

\section{Driver educator question probes}

From what you have just heard, what are your first impressions of the GDE framework? Could it fit in with the driver education course? 
If you had to prioritise instruction of vehicle manoeuvring, mastery of traffic situations, goals and contexts of driving, or goals for life and skills for living, which one would it be?

How feasible would it be to teach a course that covers all of the GDE levels? How feasible is this for driver education providers to teach in general?

Note. During the focus groups the facilitators referred to the driver education and training organisation and course by name.

251

As the GDE was used to frame the current study, the thematic analysis demanded a more structured, top-down approach to the coding than in other more inductive qualitative approaches (Braun \& Clarke, 2006). First, portions of transcribed text were assigned as being indicative of GDE levels or Person-specific factors. The same text elements could be assigned both a GDE level and Person-specific factor but could not be assigned more than one GDE level or more than one Personspecific factor. There were no specific constraints on the amount of text within each transcript that could have a single code assigned. Rather the priority was placed on capturing latent instances of a particular GDE level or Person-specific factor. However, facilitator comments were not coded and, in most cases, codes were applied to comments made by individuals rather than crossing over discussions involving multiple participants.

The main facilitator (DR), who is the first author, coded each transcript while a randomly selected subsample of two driver educator and two young driver focus group transcriptions were coded independently by the second facilitator (AH). After this, the coders met and discussed the codes they had applied. The discussion was focused on text elements that had been coded differently by each facilitator and ensuring that each text element that was included in the analysis had been coded appropriately with a single GDE level, Person-specific factor, or unique combination of these. A number of codes were modified as a result of these discussions. After the initial discussion, percentage agreement between the independent coders ranged between $84.13 \%$ and 99.48\% ( $M_{\text {agreement }}=92 \%, S D=4.0 \%$ ) depending upon the particular code and focus group being examined. Discussion continued until consensus between the coders was reached. 
Text items that had been coded with both a GDE level and a Person-specific factor then

guided the analysis. Working with the set of young driver transcripts, the number of text elements (e.g. word, phrase, sentence etc.) which were specifically coded with one of the twelve possible code combinations in the GDE matrix (e.g. Risk-increasing factors and Goals and contexts of driving) was obtained. Following this, the total number of text elements which were represented with any combination of GDE level and Person-specific factor was obtained. The first number was divided by the second number and then multiplied by one hundred to obtain the percentage amount that the specific code combination represented the total number of text elements that were coded with both a GDE level and Person-specific factor. This process was repeated for each of the twelve GDE level and Person-specific factor combinations in the matrix and replicated with transcripts from the driver educator focus groups. Text which was not coded with both a GDE level and Person-specific factor is therefore not included in the analysis.

By highlighting these co-occurring codes, all instances in the transcriptions that corresponded directly to the twelve unique target areas making up the GDE matrix were identified, greatly expanding the evaluative scope possible in the study. Moreover, by converting frequency counts to percentages the codes that were applied to each transcript become comparable both within and across the young driver and driver educators focus groups. For example, examining the transcripts this way allowed instances in the text where young drivers talked about knowledge and skills related to Mastery of traffic situations (Level Two) to be scrutinised, and to be compared and contrasted with similarly coded text elements in the other young driver or driver educator focus groups. The qualitative examination of the transcripts was guided by the results of the frequency calculations and focused on the GDE components and combinations that had the largest and smallest percentages of discussion. Illustrative quotes are provided throughout the results and discussion section. The speaker is identified according to the focus group they participated in (e.g. YND1= participant in young driver group 1; DE1 = participant in driver educator group 1).

\section{Results and discussion}


The focus groups were centred on a particular driver education course in which all

299

300

301

302

303

304

305

participants had been involved, either as a participant or driver educator. Both the young drivers and the driver educators perceived that each of the possible GDE level and Person-specific factor combinations had been present during the two day course (see Table 3). This is especially the case for the driver educators who agreed that "it pretty much describes what we do" (DE3). However, there were both similarities and differences in the amount of discussion of different GDE components in the young driver and driver educator focus groups.

Table 3.

The percentage of text elements coded as specific GDE level and Person-specific factor combinations in the young driver and driver educator focus groups.

\begin{tabular}{lllc}
\hline Knowledge & Risk-increasing & Self-evaluation & Percentage \\
and skills (\%) & factors (\%) & and awareness & of GDE- \\
& & skills (\%) & related \\
& & & Text (\%) \\
\hline
\end{tabular}

Goals for life/skills for living

(Level Four) (\%)

Young drivers

Driver educators
2.5

6.1
4.3

12.6
5.1

8.9

27.6

Goals and contexts for driving

(Level Three) (\%)

Young drivers

8.4

7.0

Driver educators

7.9

4.2

18.2

Mastery of traffic situations

(Level Two) (\%)

Young drivers

11.7

7.0

36.6

Driver educators

9.3

7.5

7.5

24.3

Vehicle Manoeuvring

(Level One) (\%)

Young drivers

23.0

4.5

2.9

30.4 
Driver educators

Percentage of GDE-related text (\%)

Young drivers

Driver educators
12.6

49.1

34.1
8.4

28.9

36.4
8.9

29.9

Note. GDE = Goals for Driver Education; Percentages were calculated by obtaining the number of text elements that were coded with a specific combination of GDE level and Person-specific factor specified in the GDE matrix, obtaining the total number of text elements that were coded with any combination of GDE level and Person-specific factor, and dividing the first number by the second one and multiplying by 100 . Calculations were performed separately for the young driver and driver educator transcripts.

\subsection{Perceptions of the young driver education and training course focus}

In general, the percentage amounts of combined GDE level and Person-specific factors indicate that the young drivers were more likely to speak about driving specific factors (e.g. GDE level one and level two) than more abstract influences on driving (e.g. GDE level three and level four). Young drivers were also much more likely to talk about Knowledge and skills related to these levels than the other Person-specific factors. All young driver groups mentioned, for example, "a particular type of driving, steering, they call it push/pull steering" (YND5). The most common combination of GDE level and Person-specific factor for the young drivers was Knowledge and skills and Vehicle manoeuvring (Level One) making up $23.0 \%$ of the total number of coded text elements. The least frequently discussed combination by the young drivers was Knowledge and skills and Goals for life/skills for living (Level Four). As such, it appears the young drivers perceived that the course they attended was heavily focused on education and training of basic driving skills and to a much less extent more abstract influences identified in the GDE framework.

For the driver educators, relatively equal percentage frequencies were found for Vehicle manoeuvring (Level One) (29.9\%) and the highly abstract and macro-contextual level Goals for life/skills for living (Level Four) (27.6\%). The least amount of discussion by the driver educators was 
discussed most among the Person-specific factors but there was relatively little difference in the proportions that each Person-specific factor was discussed overall (between $7 \%$ and $4.7 \%$ ). This contrasted with the young drivers where differences between the amounts of discussion of each Person-specific factor were quite large (between $27.1 \%$ and $6.9 \%$ ). The most common combinations discussed by the driver educators were Vehicle manoeuvring (Level One) with Knowledge and skills and Goals for life/skills for living (Level Four) and Risk-increasing factors, which were discussed in equal proportions (12.6\%). However, Goals and contexts of driving (Level Three) and Self-evaluation and awareness skills was the combination least likely to be discussed by the driver educators (4.2\%).Thus it appears that the driver educators perceive that there is at least some focus in the course on both basic driving skills and more abstract influences related to driving.

There may be implications for the driver education organisation if young drivers and driver educators have different perceptions of the main focus of the driver education course. For example, the driver educators may perceive they have provided a comprehensive driver education course that effectively focuses on the major factors affecting young driver behaviour identified in the GDE. At the same time, the young drivers may have perceived that the course is mostly focused on more basic driver training located at lower levels of the GDE. The young drivers thus may come away from the course erroneously thinking they have received complete instruction regarding the most important aspects of driving while not comprehending some of the most important contributors to young driver crash involvement. The misalignment of young driver and driver educator perceptions may mean that there is no indication for the driver education organisation that the course should be changed, expanded in its scope, or that the way that course components are delivered should be modified to potentially increase its effectiveness.

\subsection{General perceptions of GDE level and Person-specific factor combinations}

There was less variability in how the GDE levels and Person-specific factors were discussed in conjunction with each other in the driver educator focus groups compared to the young driver 
groups. The coefficient of variation ${ }^{1}$, for example, for all possible GDE component combinations in the driver educator transcripts (31\%) was much lower than in the young driver transcripts (61\%).

This indicates that the young drivers were more likely to talk about a range of GDE level and Personspecific factor combinations whereas driver educators were more likely to discuss specific reoccurring GDE level and Person-specific factor combinations. Tentatively, it seems that the driver educators' grouped together particular levels of the GDE hierarchy with particular Person-specific factors when discussing the content and structure of the course. The implication is that some driver educators may skew the education and training that they provide to young drivers, potentially overemphasising some aspects of the GDE to the neglect of other important components of driver education and training identified in the matrix.

The GDE does not stipulate that each of the twelve GDE level and Person-specific factor combinations should be weighted equally in importance. However, it is suggested that all GDE levels and Person-specific factors should be attended to in some way in driver education and training courses (Hatakka, et al., 2002). The consequences of including a greater focus on a particular GDE level, Person-specific factor, or combination of these, are currently unknown. Moreover, it may be of greater importance to examine which GDE component or combinations of components receive greater attention and ensure that the focus is on the parts of the framework that are most effective at reducing young driver crashes. Reflecting the general lack of clarity in novice driver education and training research (Simons-Morton \& Ehsani, 2016), however, little guidance is given regarding this, other than that the higher levels are most likely to be more important in influencing the driving behaviours of individuals over the long term (Peraaho, et al., 2003). The current study identified that the young drivers perceived that the course was focused primarily on more basic driver training.

Given that young drivers are likely to obtain physical driving skills relatively quickly via both formal and informal training (Hall \& West, 1996) and, in GDL jurisdictions, much of this training would be accomplished informally with parents it seems appropriate that formal driver education and training

\footnotetext{
${ }^{1}$ The coefficient of variation is a measure of dispersion that can be used to compare the variability of different variables. It is the ratio of the standard deviation divided by the mean (Bridgmon \& Martin, 2012).
} 
should have a greater focus on the higher more abstract combinations related to Goals and contexts of driving (Level Three) and Goals for life/skills for living (Level Four).

\subsection{Perceptions of higher and more abstract GDE component combinations}

One notable aspect of the results is the large amount of discussion of aspects of education and training related to Goals for life/skills for living (Level Four) by the driver educators compared to the young drivers. In total, over twice the amount of discussion by the driver educators (27.9\%) than the young drivers (11.9\%) was related to this GDE level. The abstract combination of Goals for life and skills for living and Risk-increasing factors was one of the two GDE component combinations discussed most by the driver educators. This suggests that the driver educators at least considered some of the more intangible factors affecting young drivers or attempted to teach students about these more high level or abstract driving influences. Looking at the transcripts, it appears that the educators perceived they were providing instruction at the lower GDE levels as a gateway to communicating higher level insights or knowledge. This notion is concretely verbalised by an educator who stated "well some of our early activities on all the courses certainly cover [GDE levels] one and two, so the figure eight and slalom, that's about vehicle manoeuvring, but it's more, it's starting to work on these as well (points to higher levels on GDE handout)" (DE1). Reiterating this, another educator commented that "it's not the driving skills that we're actually focussed on, we've got to use the motor car to prove stuff but we're really trying to show them that...they need to be a lot more cautious in a motor car than what they thought and it's much easier to crash a motor car than what they thought" (DE3). However, the results of the focus groups with young drivers suggest this was not an effective pedagogical strategy.

The analysis of the young driver transcripts indicated very low proportions of discussion centred on Goals for life/skills for living (Level Four). For example, the young drivers spent less than half the time than the driver educators in discussion of driver education that related to Personspecific factors associated with Goals for life/skills for living (Level Four) but nearly double the amount of time in discussion of knowledge and skills related to vehicle manoeuvring. This suggests 
400

401

402

403

404

405

406

407

408

409

410

411

412

413

414

415

416

417

418

419

420

421

422

423

424

that the young drivers did not consciously understand the intent of the driver educators that training at the lower, driving-specific levels of the GDE should be connected with aspects of driving related to the higher, more abstract GDE levels. As such, it may be more beneficial for young driver safety outcomes to provide education on aspects related to Goals for life/skills for living (Level Four) in a more direct manner.

Driver overconfidence and its connection to driving errors, violations, lapses and other adverse outcomes has been examined in previous research (Wohleber \& Matthews, 2016). Driver overconfidence can be defined as an inaccurate self-perception of driving ability compared to actual driving ability combined with a perception of unique immunity to higher levels of risk compared to similar others (Matthews \& Moran, 1986). Both experienced and inexperienced drivers are likely to have some inaccuracies in their self-assessment of driving ability or beliefs about personal susceptibility to risk (Svenson, 1981). However, some research suggests that driver overconfidence may be more prominent in young drivers, particularly young males (Matthews \& Moran, 1986; Wohleber \& Matthews, 2016).

In connection with the GDE, driver overconfidence seems to be captured as underdeveloped Self-evaluation and awareness skills, particularly related to Vehicle manoeuvring (Level One) and Mastery of traffic situations (Level Two). However, discussion of Self-evaluation and awareness skills regarding Vehicle manoeuvring (Level One) made up only $2.9 \%$ of all the text elements from the young driver groups. In comparison, the proportion of text elements assigned to this combination in the driver educator discussions was $8.9 \%$. Self-evaluation and awareness skills and Mastery of traffic situations (Level Two) were combined $7.0 \%$ of the time by the young drivers and $7.5 \%$ of the time by the driver educators. As such, there was a disparity in the amount of discussion of self-evaluation and awareness skills at the most basic level of driving a car but both groups attended equally to this Person-specific factor when discussing education and training that centred on traffic interactions. Nevertheless, in terms of the total percentage frequencies, these 
combinations were relatively small, making up only $9.9 \%$ of the young driver and $16.4 \%$ of the driver educator discussions. they're not as good as they thought they are and we're in a really good situation [to] prove it to them in a really safe environment" (DE2). Similarly, another educator described a driving task completed on the skid pan which was conducted with the intention of showing them "how very small changes in speed made 'em crash and hit that cone"(DE2). This activity aimed to "level up their actual ability with their perception of ability" (DE2). These comments seem to be related to driver educator attempts to influence the level of driving overconfidence present in many young drivers. Although, given the low proportion of time spent discussing this GDE level and Person-specific factor combination overall, it does not appear to be a priority topic for these educators. This is mirrored in the young driver transcripts with the low percentage frequency suggesting that they did not perceive the course they attended was particularly focused on calibrating their perceptions of capability with the objective reality of their skill level.

Finally, the pattern of discussion that emerged in the analysis suggests that, across the Person-specific factors, the driver educators tended to pay least amount of attention to education and training related to Goals and contexts of driving (Level Three). The driver educators acknowledged the potential importance of peers and other social driving influences on young drivers in the focus groups. One driver educator discussed a part of the course in which videos of young people who have been hurt or disabled in a crash are played. It seems that the idea of this part of the course is to stimulate reflection in the students about how drink driving may personally affect 447 the driver, their friends, and their family. This is exemplified with the comment "there's no way in 448 the world I'd feel happy about seeing my mate sittin' in that chair and I watched him get into that 449 car half pissed and drive off...l'd feel some guilt for that, you know, and so we bring all that round and have a group discussion about it" (DE2). However, the discussion of psychosocial influences on 
driving, such as alcohol and substance use and peer pressure, was relatively superficial and did not appear to be a major focus for the driver educators in the current study. This is indicated by another comment from the same educator who said "we can't go into a lot of details [in a two day course] but the main things that affect the young ones is peer group pressure, substance abuse, fatigue, road rage, things like that...I think we touch on some of this probably as best we could" (DE2). The limited discussion of Goals and contexts of driving (Level Three) by the driver educators is reflected in the perceptions of the young drivers. This GDE level was discussed infrequently by the young drivers compared to the two more driving-specific GDE levels. The main way that the young drivers talked about this GDE level was in reference to a new awareness that peer passengers were a potential source of distraction for the driver. For example, one young driver talked about how she now reminded herself to stay focused when driving because she had "just picked up four friends who are off to this really exciting thing but [she] said [she] would drive" (YND1).

While driver distraction is an important issue that contributes to driver errors and crashes for young drivers (Young \& Salmon, 2012), Goals and contexts of driving (Level Three) is also wider in scope encompassing other motivational and psychosocial driving influences. For example, Hatakka, et al. (2002) suggest that the decision whether to drive or to take public transport would be located on this level. Peer engagement and social life is an important aspect of adolescent development (Hoffnung, 2013) and young people often socialise at events (e.g. parties) or locations where alcohol or other illicit substances that effect driving ability may be consumed (Lipperman-Kreda, Mair, Bersamin, Gruenewald, \& Grube, 2015; Mair, Lipperman-Kreda, Gruenewald, Bersamin, \& Grube, 2015). Furthermore, these events often occur late at night or continue into the early hours of the morning. Statistics indicate that young drivers have heightened risk of crashing in the evening and at night on the weekend (Beanland, et al., 2013; Mair, et al., 2015; Thomas \& Jones, 2014). However, there was next to no discussion of drink-driving, non-distraction related peer factors such as peer pressure, driving late at night or other non-driving situational or contextual influences on driving by 
the young drivers. This is not surprising given the apparent lack of focus on Goals and contexts of driving (Level Three) by the driver educators.

Some young people may take risks simply because a risk-taking opportunity arises from which they have not experienced any adverse consequences (Gibbons, Gerrard, \& Lane, 2003). That is, a young driver may find themselves in a non-driving situation or context that is conducive to taking driving risks, such as attending a party with no alternative method of returning home other than driving. It is conceivable that a young driver's self-awareness of how they personally are likely to act in driving-related contextual situations would impact upon their ability to recognise the risks they face and to put into action the knowledge and skills they have to alleviate or reduce these risks. As such, equipping young drivers to make a choice to drive to these events or not and giving them strategies to avoid or minimise their involvement in situations that may impair their driving ability may be a particularly important facet of young driver education. The apparent low priority of the Goals and contexts of driving (Level Three) by the driver educators in the current study is thus surprising. Arguably, given research suggesting that young drivers obtain physical driving skills relatively quickly (Deery, 1999) and that other contextual factors feature prominently in the driving behaviours of this group (Shope \& Bingham, 2008), Goals and contexts of driving (Level Three), broadly, should be a more specific focus of driver educators.

\section{Strengths and Limitations}

A key strength of this study is the high level of methodological rigour. The study was approached with an underlying phenomenological philosophy that ensured that the authentic 'voice' of the participants was prioritised while the GDE was utilised to structure the analysis and impose a level of order and efficiency in the data collection and analysis. Some criticism exists regarding the non-scientific nature of much evaluation research in traffic psychology (Glendon, 2011). The focus on applying the GDE framework in a practical way ensured that the research was both systematic and theoretically grounded. The continued involvement of the same facilitators throughout all of the focus groups ensured consistency in the data collection. Bias in the analysis was reduced by the 
independent coding of transcripts by the two facilitators. A further strength of the current study is the collection and analysis of data from both young drivers and driver educators. These two groups are interdependent and inherently involved in the process of learning to drive but differ greatly in their respective levels of interest, motivation, experience and knowledge. The dataset obtained was rich and allowed a depth of understanding that would not be possible with the use of quantitative self-report or purely observational study designs.

Despite these strengths, there are some limitations which require acknowledgement. The application of a categorical theoretical framework to a continuous flow of dialogue was challenging and some issues were encountered in this process. While being a comprehensive and organised theoretical framework, it appears that little development has occurred in the time since the theory was originally designed. The demarcations between the hierarchical levels and between the Personspecific factors are at times unclear and this made making concrete assignment of specific codes to specific text elements difficult. The high level of agreement between independent coders, however, is suggestive of an unbiased understanding of the GDE and its application to the transcribed focus group texts. Future theoretical development of the GDE would serve to alleviate these issues. While it is possible that the GDE presentation to driver educators may have influenced the way in which the driver educators responded in the focus groups, care was taken to only provide information in an impartial way. Care was also taken at the beginning of each focus group to ensure the driver educators were comfortable speaking honestly and openly in the groups setting. As such it is unlikely that the driver educator responses would have biased due to the additional information they received regarding the GDE. It is possible that not presenting the same GDE information to the young drivers could have led to differences in responses by these participants compared to the driver educators, particularly about the higher levels and more abstract components of the GDE. However, it is likely that the young drivers participants provided a more organic and authentic discussion of their experiences by using the indirect questions. Thus the differences in methodology between the driver educator and young driver focus groups is likely to have contributed to the 
nature of the findings by taking into account the amount of experience with driver education and training of each participant type.

Finally, the fact that participants were all involved with a single course at a particular organisation may limit the generalisability of the study. However, driver education is not mandated in Queensland and a great variety of driver education and training has been developed. It is possible that young drivers attending driver education and training courses within Queensland would be exposed to very different course curriculums. Thus, the requirement that young drivers had completed the course at the organisation also ensured that both the young drivers and driver educators were discussing a somewhat standardised experience of driver education. Future studies could apply a different methodology to obtain a more diverse sample, such as individual qualitative interviews with driver trainers and their students. A quantitative analysis of a driver education course with questions derived directly from the GDE matrix may also be of value.

\section{Practical applications}

A number of practical applications arise from the current study. First, the intuitive method of applying codes corresponding to the GDE levels and Person-specific factors to the focus group transcripts provided a rich, detailed and organised data set for qualitative analysis. This process could readily be applied to other forms of text-based qualitative data related to driver education and training. The usability and flexibility of this process and the scientific underpinning of the GDE may increase the rigour of evaluation research regarding driver education and training. Second, the insights gained in the current study using the GDE to evaluate a particular young driver education course can be applied to the design of future driver education and training programs. Using this process it became evident that young driver and driver educator perceptions of the focus of the education they received may differ substantially. Finally, the study offered some evidence-based suggestions regarding the GDE components that should be prioritised in young driver training. It is recommended that training relating to the higher levels of the GDE, particularly Goals and contexts 
for driving (Level Three) and Self-evaluation and awareness skills be highlighted in future young driver education and training programs.

\section{Conclusion}

This study compared the perceptions that young drivers and driver educators had of a driver

557 education and training. The GDE was operationalised and used to direct both the data collection and analysis. The results indicated that the young drivers receiving the driver education and training perceived what they were learning differently to what the driver educators perceived they were teaching. The students did not perceive that they were learning much about the higher levels of the GDE framework. In comparison, it appeared that the driver educators believed they were providing instruction covering the whole of the GDE. Moreover, the driver educators appeared to believe that they were using more basic skills-based training to also provide education and training about more abstract and less driving-specific influences on driving. Notwithstanding that the young novice drivers were not provided with the GDE matrix as part of the discussion, the misalignment of perceptions between young drivers and driver educators indicates that this may not be a particularly effective training strategy. It is recommended that driver educators should focus on providing information based on these higher more abstract levels in a more explicit manner. To date, evaluations of traditional driver education and training have not unequivocally demonstrated that safer young drivers result from participation in these programs. However, it is possible that systematically designed, broadly focused and scientifically-underpinned driver education and training programs may, in the future, complement GDL programs as an effective young driver safety countermeasure. The results from this study may assist in the design of more effective driver

574 education and training programs in order to reduce young driver crash rates. 
577 The research team would like to acknowledge Sharlene Makin and colleagues for assistance with

578 recruitment and the use of facilities to conduct the focus groups.

579 Funding source

580 This research was supported by the Australian Government through the Australian Research

581 Council's Linkage Projects funding scheme (project LP140100409). 
602

603

604

605

606

607

608

609

610

611

612

613

614

615

616

617

618

619

620

621

622

623
References

Bates, L., Watson, B., \& King, M. J. (2014). The role of parents and non-parents in the supervision of learner drivers in Australia. Accident Analysis \& Prevention, 70, 40-45.. doi:10.1016/j.aap.2014.03.004

Bates, L. J., Allen, S., Armstrong, K., Watson, B., King, M. J., \& Davey, J. (2014). Graduated Driver Licensing: An international review. Sultan Qaboos University Medical Journal, 14(4), e432e441.Retrieved from http://www.ncbi.nlm.nih.gov/pmc/articles/PMC4205052/

Bates, L. J., Davey, J., Watson, B., King, M. J., \& Armstrong, K. (2014). Factors contributing to crashes among young drivers. Sultan Qaboos university medical journal, 14(3), 297-305.

Beanland, V., Goode, N., Salmon, P. M., \& Lenné, M. G. (2013). Is there a case for driver training? A review of the efficacy of pre- and post-licence driver training. Safety Science, 51(1), 127-137. doi:10.1016/j.ssci.2012.06.021

Berg, H. Y. (2006). Reducing crashes and injuries among young drivers: what kind of prevention should we be focusing on? Injury Prevention, 12(Suppl 1), i15-i18. doi:10.1136/ip.2006.012062

Borowsky, A., Shinar, D., \& Oron-Gilad, T. (2010). Age, skill, and hazard perception in driving. Accident Analysis \& Prevention, 42(4), 1240-1249. doi:10.1016/j.aap.2010.02.001

Bradshaw, C., Turner, B., Makwasha, T., \& Cairney, P. (2015). Road fatalities and serious injuries in Australia and New Zealand 2001-10. Sydney Austroads.

Braun, V., \& Clarke, V. (2006). Using thematic analysis in psychology. Qualitative Research in Psychology, 3(2), 77-101. doi:10.1191/1478088706qp063oa

Bridgmon, K. D., \& Martin, W. E. (2012). Quantitative and Statistical Research Methods. Somerset, United States: John Wiley \& Sons, Incorporated.

Christie, R. (2001). The effectiveness of driver training as a road safety measure: an international review of the literature Paper presented at Australasian Road Safety Research, Policing and Education Conference Melbourne, Victoria. Retrieved from http://acrs.org.au/files/arsrpe/RS010018.pdf

Constantinou, E., Panayiotou, G., Konstantinou, N., Loutsiou-Ladd, A., \& Kapardis, A. (2011). Risky and aggressive driving in young adults: Personality matters. Accident Analysis \& Prevention, 43(4), 1323-1331. doi:10.1016/j.aap.2011.02.002 
Curry, A. E., Hafetz, J., Kallan, M. J., Winston, F. K., \& Durbin, D. R. (2011). Prevalence of teen driver errors leading to serious motor vehicle crashes. Accident Analysis \& Prevention, 43(4), 12851290. doi:10.1016/j.aap.2010.10.019

Deery, H. A. (1999). Hazard and Risk Perception among Young Novice Drivers. Journal of Safety Research, 30(4), 225-236. doi:10.1016/S0022-4375(99)00018-3

Elvik, R., Hoye, A., Vaa, T., \& Sorenson, M. (2009). Handbook of Road Safety Measures (2nd ed.). Bingley, UK: Emerald, Inc.

Engstrom, I., Gregersen, N. P., Hernetkoski, K., Keskinen, E., \& Nyberg, A. (2003). Young novice drivers, driver education and training, literature review. Sweden: VTI.

Farmer, C. M., \& Wells, J. K. (2015). Crash and citation records of young drivers with skid avoidance training. Arlington, VA: Insurance Institute for Highway Safety.

Gibbons, F. X., Gerrard, M., \& Lane, D. J. (2003). A Social Reaction Model of Adolescent Health Risk. In J. Suls \& K. A. Wallston (Eds.), Social Psychological Foundations of Health and Illness (pp. 107-136). Malden: Blackwell Publishing.

Glendon, A. I. (2011). Traffic Psychology. In IAAP Handbook of Applied Psychology (pp. 543-558): Wiley-Blackwell.

Glendon, A. I., McNally, B., Jarvis, A., Chalmers, S. L., \& Salisbury, R. L. (2014). Evaluating a novice driver and pre-driver road safety intervention. Accident Analysis \& Prevention, 64, 100-110. doi:10.1016/j.aap.2013.11.017

Gregersen, N. P. (1996). Young drivers' overestimation of their own skill-an experiment on the relation between training strategy and skill. Accident Analysis \& Prevention, 28(2), 243-250. doi:10.1016/0001-4575(95)00066-6

Groeger, J. A. (2011). How many E's in road safety? In B. E. Porter (Ed.), Handbook of Traffic Psychology. Saint Louis: Elsevier Science

Hall, J., \& West, R. (1996). Role of formal instruction and informal practice in learning to drive. Ergonomics, 39(4), 693-706. doi:10.1080/00140139608964490

Hatakka, M., Keskinen, E., Gregersen, N. P., Glad, A., \& Hernetkoski, K. (2002). From control of the vehicle to personal self-control; broadening the perspectives to driver education. Transportation Research Part F: Traffic Psychology and Behaviour, 5(3), 201-215. doi:10.1016/S1369-8478(02)00018-9 
679

680

681

682

683

684

685

686

687

688

689

690

691

692

693

694

695

696

697

698

699

700

701

702

703

704

705

706

707

708

Haworth, N., Kowadlo, N., \& Tingvall, C. (2000). Evaluation of pre-driver education program. Victoria Monash University Accident Research Centre.

Hoeschen, A., Verwey, W., Bekiaris, E., Knoll, C., Widlroither, H., de Ward, D., \& Schelin, H. (2001). TRAINER: System for driver training and assessment using interactive evaluation tools and reliable methodologies. Brussels, Belgium: European Commission Competitive and Sustainable Growth Programme Directorate General for Energy and Transport.

Hoffnung, M. (2013). Lifespan Development: A Chronological Approach (2nd ed.). Milton, Qld: John Wiley and Sons Australia.

Institute for Health Metrics and Evaluation. (2015). GBD Compare Retrieved 24th October 2016, from University of Washington, http://vizhub.healthdata.org/gbd-compare/

Ker, K., Roberts, I., Collier, T., Beyer, F., Bunn, F., \& Frost, C. (2005). Post-licence driver education for the prevention of road traffic crashes: a systematic review of randomised controlled trials. Accident Analysis \& Prevention, 37(2), 305-313. doi:10.1016/j.aap.2004.09.004

Langley, J. D., Wagenaar, A. C., \& Begg, D. J. (1996). An evaluation of the New Zealand Graduated Driver Licensing System. Accident Analysis \& Prevention, 28(2), 139-146. doi:10.1016/00014575(95)00040-2

Lipperman-Kreda, S., Mair, C. F., Bersamin, M., Gruenewald, P. J., \& Grube, J. W. (2015). Who drinks where: Youth selection of drinking contexts. Alcoholism: Clinical and Experimental Research, 39(4), 716-723. doi:10.1111/acer.12670

Lonero, L., \& Mayhew, D. (2010). Teen driver safety: Large-scale evaluation of driver education review of the literature on driver education evaluation 2010 update. Washington, DC.: AAA Foundation for Traffic Safety.

Lonero, L. P. (2008). Trends in Driver Education and Training. American Journal of Preventive Medicine, 35(3, Supplement), S316-S323. doi:10.1016/j.amepre.2008.06.023

Lund, A. K., Williams, A. F., \& Zador, P. (1986). High school driver education: Further evaluation of the Dekalb County study. Accident Analysis \& Prevention, 18(4), 349-357. doi:10.1016/00014575(86)90048-5

Mair, C., Lipperman-Kreda, S., Gruenewald, P. J., Bersamin, M., \& Grube, J. W. (2015). Adolescent drinking risks associated with specific drinking contexts. Alcoholism: Clinical and Experimental Research, 39(9), 1705-1711. doi:10.1111/acer.12806

Mäntylä, T., Karlsson, M. J., \& Marklund, M. (2009). Executive control functions in simulated driving. Applied Neuropsychology, 16(1), 11-18. doi:10.1080/09084280802644086 
709

710

711

712

713

714

715

716

717

718

719

720

721

722

723

724

725

726

727

728

729

730

731

732

733

734

735

736

737

738

739

740

741

742

743

744

745

746

747

748

749

Matthews, M. L., \& Moran, A. R. (1986). Age differences in male drivers' perception of accident risk: The role of perceived driving ability. Accident Analysis \& Prevention, 18(4), 299-313. doi:10.1016/0001-4575(86)90044-8

Mayhew, D., Simpson, H., \& Robinson, A. (2002). The safety value of driver education an training. Injury Prevention, 8(Suppl 2), ii3-ii8. Retrieved from PMC. Retrieved from http://www.ncbi.nlm.nih.gov/pmc/articles/PMC1765489/.doi:10.1136/ip.8.suppl_2.ii3

Mayhew, D., Simpson, H., Williams, A., \& Ferguson, S. (1998). Effectiveness and Role of Driver Education and Training in a Graduated Licensing System. Journal of Public Health Policy, 19(1), 51-67. doi:10.2307/3343089

McCartt, A. T., Mayhew, D. R., Braitman, K. A., Ferguson, S. A., \& Simpson, H. M. (2009). Effects of age and experience on young driver crashes: Review of recent literature. Traffic Injury Prevention, 10(3), 209-219. doi:10.1080/15389580802677807

Merkel, R. L., Nichols, J. Q., Fellers, J. C., Hidalgo, P., Martinez, L. A., Putziger, I., . . Cox, D. J. (2013). Comparison of on-road driving between young adults with and without ADHD. Journal of Attention Disorders, 20(3), 260-269. doi:10.1177/1087054712473832

Monárrez-Espino, J., Hasselberg, M., \& Laflamme, L. (2006). First year as a licensed car driver: Gender differences in crash experience. Safety Science, 44(2), 75-85. doi:10.1016/j.ssci.2005.07.004

Nvivo 11 Pro. (2016). Nvivo qualitative data analysis Software (Version 11): QSR International Ltd.

Peck, R. C. (2011). Do driver training programs reduce crashes and traffic violations? - A critical examination of the literature. IATSS Research, 34(2), 63-71. doi:10.1016/j.iatssr.2011.01.001

Peraaho, M., Keskinen, E., \& Hatakka, M. (2003). Driver competence in a hierarchical perspective; implications for driver education. Finland University of Turku, Traffic Research.

Queensland Department of Transport and Main Roads. (2016). Getting a licence. Retrieved 24th November 2016, from TMR, http://www.tmr.qld.gov.au/Licensing/Getting-a-licence

Raftery, S. J., \& Wundersitz, L. N. (2011). The efficacy of road safety education in schools: A review of current approaches. Adelaide: Centre for Automotive Safety Research (CASR).

Roberts, I., \& Kwan, I. (2001). School based driver education for the prevention of traffic crashes. Cochrane Database Syst Rev(3), Cd003201. doi:10.1002/14651858.cd003201 
Royal Automobile Club of Victoria. (2016). The effectiveness of driver training/education as a road safety measure.Noble Park North: RACV.

Senserrick, T. M., \& Williams, A. F. (2015). Summary of literature of the effective components of graduated driver licensing systems. Sydney: Austroads Ltd.

Shope, J. T. (2007). Graduated driver licensing: Review of evaluation results since 2002. Journal of Safety Research, 38(2), 165-175. doi:10.1016/j.jsr.2007.02.004

Shope, J. T., \& Bingham, C. R. (2008). Teen Driving: Motor-Vehicle Crashes and Factors That Contribute. American Journal of Preventive Medicine, 35(3, Supplement), S261-S271. doi:10.1016/j.amepre.2008.06.022

Simons-Morton, B., \& Ehsani, P. J. (2016). Learning to Drive Safely: Reasonable Expectations and Future Directions for the Learner Period. Safety, 2(4). doi:10.3390/safety2040020

Svenson, O. (1981). Are we all less risky and more skillful than our fellow drivers? Acta Psychologica, 47(2), 143-148. doi:10.1016/0001-6918(81)90005-6

Thomas III, F. D., Blomberg, R. D., \& Fisher, D. L. (2012). A Fresh Look at Driver Education in America. Washington, D.C.: NHTSA.

Thomas, J. R. V., \& Jones, S. J. (2014). Injuries to 15-19-year olds in road traffic crashes: a cross sectional analysis of police crash data. Journal of Public Health, 22(3), 245-255. doi:10.1007/s10389-014-0617-8

Tronsmoen, T. (2008). Associations between self-assessment of driving ability, driver training and crash involvement among young drivers. Transportation Research Part F: Traffic Psychology and Behaviour, 11(5), 334-346. doi:10.1016/j.trf.2008.02.002

Tronsmoen, T. (2010). Associations between driver training, determinants of risky driving behaviour and crash involvement. Safety Science, 48(1), 35-45. doi:10.1016/j.ssci.2009.05.001

Vanlaar, W., Mayhew, D., Marcoux, K., Wets, G., Brijs, T., \& Shope, J. (2009). An evaluation of graduated driver licensing programs in North America using a meta-analytic approach. Accident Analysis \& Prevention, 41(5), 1104-1111. doi:10.1016/j.aap.2009.06.024

Voogt, A., Day, A., \& Baksheev, G. N. (2014). Risky driving in young adults: A review of the literature Road \& Transport Research: A Journal of Australian and New Zealand Research and Practice, 23(2), 50-59. 
Wohleber, R. W., \& Matthews, G. (2016). Multiple facets of overconfidence: Implications for driving safety. Transportation Research Part F: Traffic Psychology and Behaviour, 43, 265-278. doi:10.1016/j.trf.2016.09.011

World Health Organisation. (2016, November 2016). Road traffic injuries. Retrieved 02 December 2016, from WHO, http://www.who.int/mediacentre/factsheets/fs358/en/

Young, K. L., \& Salmon, P. M. (2012). Examining the relationship between driver distraction and driving errors: A discussion of theory, studies and methods. Safety Science, 50(2), 165-174. doi:10.1016/j.ssci.2011.07.008 